\title{
Exploration of Procedural Knowledge of Bilingual Students in Chemical Equilibrium Problem Solving
}

\author{
Benny Yodi Sawuwu ${ }^{1 *}$, Crys Fajar Partana ${ }^{1,2}$, Hairida $^{3}$, and Ira Lestari ${ }^{3}$ \\ ${ }^{1}$ Department of Chemistry Education, Master Program, Graduate School, \\ Yogyakarta State University, Yogyakarta, Indonesia \\ ${ }^{2}$ Department of Chemistry Education, Faculty of Mathematics and Natural Sciences, \\ Yogyakarta State University, Yogyakarta, Indonesia \\ ${ }^{3}$ Department of Chemistry Education, Faculty of Teacher Training and Education, \\ Tanjungpura University, Pontianak, Indonesia \\ *Corresponding author: E-mail: bennyyodi@yahoo.com
}

\begin{abstract}
This research was conducted to explore how procedural knowledge of bilingual students in chemical equilibrium problem-solving skills. This research was a descriptive study of 31 bilingual private high school students. Chemical equilibrium problem solving skills were collected by three problems, while the procedural knowledge was collected by analysis of student answers, self-assessment metacognition questionnaire, and the interview with students and their chemistry teacher. Data collected was analyzed by a phenomenological reduction method. The results of students' procedural knowledge were categorized into assumption determination $(54,84 \%)$, strategy development $(22,58 \%)$, chemical equation $(41,94 \%)$, factors affecting the equation $(61,29 \%)$, using the other knowledge $(29,03 \%)$, quantitative analysis $(38,71 \%)$, and alternative strategy $(25,81 \%)$. According to the operator in each framework answer, the result of students' answers of chemical equilibrium problem-solving skills was classified into phenomenological and formalism answers. In phenomenological answers, students began their framework from the chemical equation to factors affecting the equilibrium shift. In the formalism answer, the students began their framework from the information given in the problems and related it to the stoichiometry and alternative ways to find the final states (goals). In this study was also found some students' errors in chemical language and chemical equilibrium conceptions.
\end{abstract}

Keywords: procedural knowledge, chemical equilibrium, problem-solving

\section{INTRODUCTION}

Chemical equilibrium is one of the most difficult chemical topics in students' perspective [1]. Some research indicated that there were identified some students' errors in chemical equilibrium as the contribution of content sequence taught [2], alternative conceptions that were elicited from textbooks used [3], the inappropriateness of analogy used [4], and from the students themselves [5]. There were two types of students' error in chemical equilibrium: systematic error for difficulty learning factor and random error for lack of relevant knowledge [5]. These error types are disclosed by the student's answer where its meaning is built from the students' knowledge of chemical equilibrium. How the discourse in the answer made is understood by Martinand's representation of modelling in science that was a dynamic scheme for linking an empirical referent (things, phenomena, and process), an interpretive elaboration (model or concept), and a cognitive matrix (operational knowledge) for explaining the construction of knowledge [6]. Based on this model, the students' answer in chemical equilibrium problem solving was classified into three 
type answers [6]. The first was a phenomenology answer for the answer that related to the phenomena and the theory directly. The second was a formalism answer for the answer that related to the knowledge just as functional and limited integrated concepts. The last was phenomenography answer for the answers that related to other relevant knowledge.

These answers can be revealed by exposing procedural knowledge of students when they were solving the problem given. Procedural knowledge was one of the sub-dimensions of metacognitive knowledge about how to solve the problem successfully [7-11]. Procedural knowledge was a knowledge about other strategy and procedure [12], procedure application, implementation in another situation, knowledge from inquiry [10], sources to localize the knowledge, and organization of learning sources [9]. This metacognition aspect tended rarely to discuss in chemical equilibrium problem-solving studies $[5,13]$, although the chemical problem solving is one of the metacognitive activities as the interaction between the mental capacity and the work of memory occurs [14].

As mentioned before that students themselves contributed in the error of chemical equilibrium problem solving, the bilingual students had more susceptible than unilingual students to that error [15]. However, other research showed that the bilingual students were more excellent on mastery their learning because of their neural activity differences [16], and some studies explained this neural differences were due to the brain differences between men and women $[17,18]$. These contrary investigations become interesting to discuss to reveal the bilingual students in their procedural knowledge on chemical equilibrium problem solving. This research was conducted to explore how the procedural knowledge of bilingual students in chemical equilibrium problem solving skills and how the gender differences on this procedural knowledge.

\section{MATERIALS AND METHODS}

This research was a descriptive study. Participants of this study were 31 bilingual private high school students in the natural sciences program of XI grade in Pontianak, Indonesia. They consisted of 16 males and 15 female students from 15-16 years old. They seated in the same class where chemistry was the compulsory subject for these participants. This class was selected purposively from other bilingual classes in that school for the maximum variance reason to get more varied procedural knowledge data. The maximum variance consideration was determined from the largest variance of the class achievement in the topics before chemical equilibrium (e.g. thermochemistry and reaction rate) and the formative evaluation in the chemical equilibrium.

Chemical equilibrium problem solving skills were collected by three problems, where the topics of the problems respectively were the peroxide dissociation, the ceramic production, and the bread making process. The problems were arranged based on the chemical problem criteria of [19]. Content validity scores by Gregory Test were 1.00 for question $1,0.89$ for question 2, and 1.00 for question 3 . The results of the preliminary field test of this instrument were of $100 \%$ relevance in both the language and the understandable statements and of $78 \%$ relevance in the thinking and comprehension level in problem-solving.

Measuring the procedural knowledge quantitatively used the self-assessment metacognition questionnaire adopted by [20] that arranged with the combination of the items of metacognitive knowledge inventory adapted from [21] and the IDEALS problem-solving steps: identify, define, enumerate, analyze, list, and self-correct [22]. The questionnaire consisted of 20 statements to explore metacognitive knowledge in chemical equilibrium problem solving skill divided into 3 parts: 8 items for declarative knowledge, 7 items for procedural knowledge, and 5 items for conditional knowledge. This instrument used a bipolar answer (yes or no). The participants should give the reason on each item if they chose either yes or no. The declarative knowledge items were used to identify the problem identification of participants (for arranging the initial state of the problem solving framework) and the conditional knowledge items were used to identify the answer examination of participants (for determining the final state of the problem solving framework). The indicators and the self-assessment statements were focused on the procedural knowledge 
domain and have been mapped toward the transition of each step in problem solving as shown in Table 1. Content validity score by Gregory Test was 0.99 . The results of preliminary field test of this instrument were of $95 \%$ relevance in both the language and the understandable statement and of $90 \%$ relevance in the assertiveness meaning. The reliability based on Cronbach Alpha was 0.75 for the whole items. Data of each item were presented for each indicator in the percentage of the student number. Data collected of procedural knowledge indicators were also presented as a gender distribution diagram (for revealing the gender aspect on the procedural knowledge) and analyzed based on the reasons why they are judging themselves for each indicator.

Table 1 Procedural Knowledge Indicators

\begin{tabular}{|l|l|l|l|}
\hline Code & $\begin{array}{l}\text { Procedural Knowledge } \\
\text { Indicator }\end{array}$ & $\begin{array}{l}\text { Problem-Solving } \\
\text { Transition }\end{array}$ & Self-assessment statement \\
\hline PK1 & Determining the assumption & Identify to Define & $\begin{array}{l}\text { I make assumption(s) to help me to solve the } \\
\text { problem given. }\end{array}$ \\
\hline PK2 & $\begin{array}{l}\text { Developing the plan from } \\
\text { the strategy chosen into subs } \\
\text { of problem }\end{array}$ & Define to Enumerate & $\begin{array}{l}\text { I develop the problem solving plan into detailed } \\
\text { steps to know to get final answer. }\end{array}$ \\
\hline PK3 & $\begin{array}{l}\text { Making the chemical } \\
\text { equation }\end{array}$ & Define to Enumerate & $\begin{array}{l}\text { I arrange chemical reaction equation from data } \\
\text { in the question given. }\end{array}$ \\
\hline PK4 & $\begin{array}{l}\text { Analyzing the factors } \\
\text { engaged in chemical }\end{array}$ & $\begin{array}{l}\text { Enumerate to } \\
\text { Analyze }\end{array}$ & $\begin{array}{l}\text { I consider the factors of chemical equilibrium } \\
\text { which concerned in the problem. }\end{array}$ \\
\hline PK5 & $\begin{array}{l}\text { Using the other knowledge } \\
\text { to solve the problem }\end{array}$ & Analyze to List & $\begin{array}{l}\text { I use other chemical equilibrium concepts to help } \\
\text { me to solve the problem given. }\end{array}$ \\
\hline PK6 & $\begin{array}{l}\text { Analyzing quantitative } \\
\text { aspects }\end{array}$ & Analyze to List & $\begin{array}{l}\text { I use stoichiometry or any } \\
\text { measurement to help me to solve the problem }\end{array}$ \\
\hline PK7 & $\begin{array}{l}\text { Thinking any possible way } \\
\text { that could be done to solve } \\
\text { the problem }\end{array}$ & List to Self-correct & $\begin{array}{l}\text { I just remember there is (are) other way(s) to } \\
\text { solve the problem given. }\end{array}$ \\
\hline
\end{tabular}

The procedural knowledge was collected qualitatively by analysis of student answers through the descriptive coding from a phenomenological reduction method [23] that began with making the transcription of the students' problem solving activities as a descriptive report for each problem. This transcription was arranged based on the students' reasons from the questionnaire and their answers. The transcription was reduced to be the codes of the procedural knowledge activities on each problem. This method found both what and how the procedural knowledge in chemical equilibrium problem solving through reduction data on each student's answer and the interpretation of them. All codes were arranged to be a framework diagram of each problem.

Semi-structured interviews with the students and their chemistry teacher were also conducted to reveal some cases found in this study such as the students' daily activities, achievements in chemistry before the test conducted, their interests in chemistry, some students' backgrounds, and some students' behaviors in the chemical problem solving before and during the test for confirming and interpreting the finding. The interview protocol could be seen in Table 2 . 
Table 2 Semi-structured Interview Protocol for Exploring the Students Procedural Knowledge in Chemical Equilibrium Problem Solving

\begin{tabular}{|c|c|}
\hline Exploring The Teacher's Perspective & Exploring The Students' Perspective \\
\hline $\begin{array}{l}\text { 1. How about your assessment toward your } \\
\text { students' chemistry achievement in cognitive, } \\
\text { psychomotor, and affective domains? (for } \\
\text { each participant) }\end{array}$ & $\begin{array}{l}\text { 1. Do you like to learn chemistry? Why? } \\
\text { 2. During you learn chemistry, what are the most difficult } \\
\text { topics you have learnt? Why? (how about chemical } \\
\text { equilibrium) }\end{array}$ \\
\hline 2. What type of problem you use to train your & How do you learn chemistry? \\
\hline students' chemical problem solving skill? & hievement in chemistry? \\
\hline $\begin{array}{l}\text { 3. What are your students errors in } \\
\text { understanding the chemical equilibrium? }\end{array}$ & $\begin{array}{l}\text { 5. If you solve a chemical problem, what will you do first? } \\
\text { Why? }\end{array}$ \\
\hline Specify the subtopics? & 6. What is an assumption? How about your assumption to \\
\hline $\begin{array}{l}\text { 4. Do your students always do their task as } \\
\text { similar as the procedure of an example? Is } \\
\text { there any students' improvisation? How? }\end{array}$ & $\begin{array}{l}\text { solve the problems given in the last test? } \\
\text { W. Why do you use the way (on the students' answer sheet) } \\
\text { to solve the problems given in the last test? }\end{array}$ \\
\hline $\begin{array}{l}\text { 5. Do your students check their answer } \\
\text { infrequently? Why? }\end{array}$ & $\begin{array}{l}\text { 8. If you cannot finish your chemical problem, what will } \\
\text { you do? }\end{array}$ \\
\hline $\begin{array}{l}\text { 6. Do your students always write down their } \\
\text { answer incompletely? Why? }\end{array}$ & $\begin{array}{l}\text { 9. If you are given more time to finish the chemical } \\
\text { problem or if the problem becomes a homework, what }\end{array}$ \\
\hline $\begin{array}{l}\text { 7. How are your students' mind when you give } \\
\text { conceptual or algorithm problems? }\end{array}$ & $\begin{array}{l}\text { will you be sure that you can solve the problem? What } \\
\text { will the result be better? What will you do? }\end{array}$ \\
\hline
\end{tabular}

\section{RESULTS AND DISCUSSION}

Figure 1 showed the attainment of students of every indicator according to the gender distribution. The percentage of the attainments showed the number of students (total), males and females, that they were positive toward the indicators. The first three indicators formed the foundation of their procedural knowledge in chemical equilibrium problem-solving. For PK1, 29.41\% of them confessed that they made the assumption as a necessity though they could not solve them, of $23.53 \%$ realized that was important for making the assumption, of $23,53 \%$ said that the assumption helped them find the goal of the problem and the easiness to solve the problem, and others said that they had to do it because their teacher taught them and if the ways were not calculated.

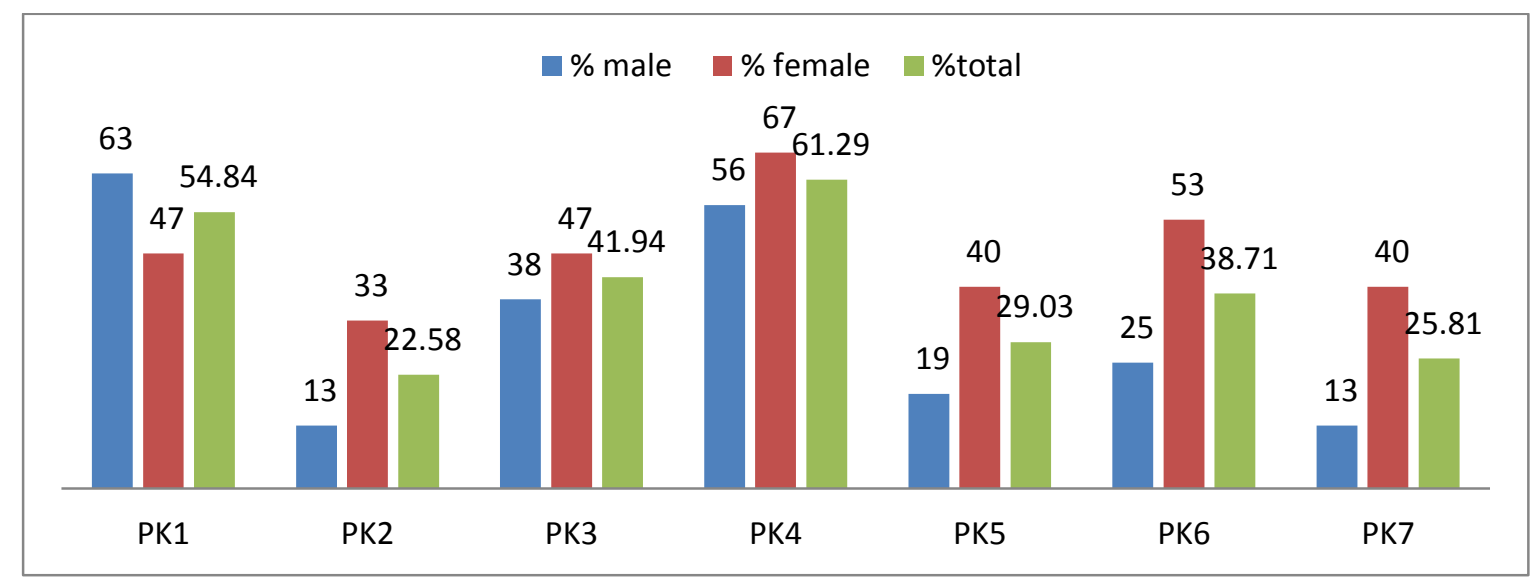

Figure 1 Percentage of student attainment in procedural knowledge

For PK2, 33,33\% of them said they had tried to think the planning but had a difficulty to find the correct way, of 20,83\% thought despondently, of $25 \%$ thought undetailed, and others thought it was made them lose their time. According their teacher, the students tended to solve the problem as their teacher or their tutor (private teacher) had taught them and to write the answer as minimum as they could get the main 
point. For PK3, of $41,94 \%$ used the chemical equation in order to solve the problem easier because they thought it was usually they did and it would help them to not leaf through the papers. In addition, of 16,13\% students used the chemical equation without rewrote them on the worksheet.

Before continuing discussing the last four indicators, we should analyze the result of the foundational indicators that is the students' framework in each problem as shown in Figure 2, 3, and 4. In every solution they posed revealed that students combine the data from the problem given with ICE scheme (initialchemical-equilibrium) or limiting reagent. Some student who had a difficulty with this ICE tended to have a difficulty to develop the strategy to solve the problem. They avoided the chemical equation and be puzzled how to use the equation.

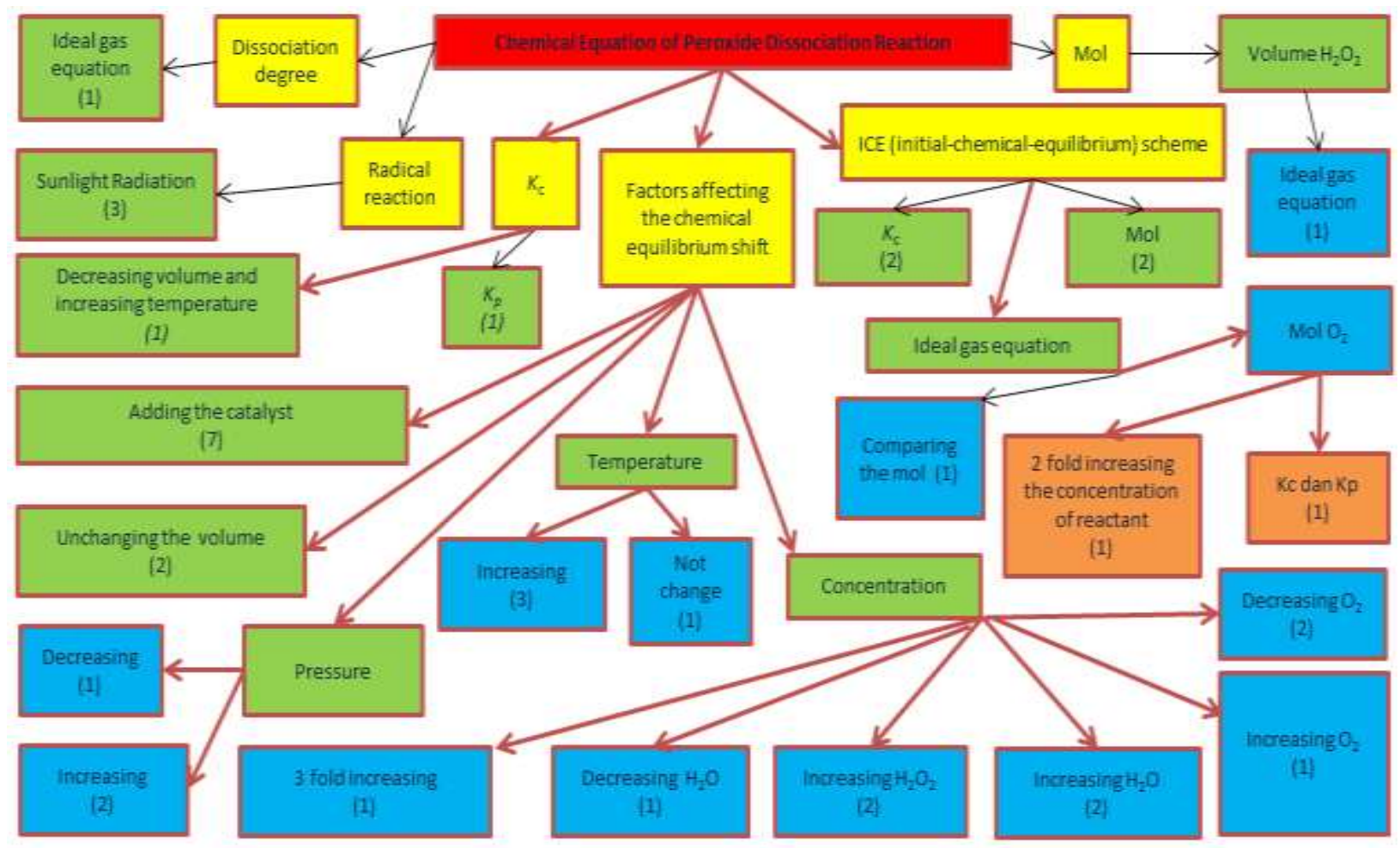

Figure 2 Distribution of Students' Framework of Problem 1

Note:

a) The Black arrow showed the ineffective ways while the red arrows showed the effective ways.

b) The red box showed the starting point of students' thinking

c) The yellow boxes showed the thematic strategies (there were 7 strategies, except for $\mathrm{K}_{\mathrm{c}}$ strategy was separated to be two strategies)

d) The process of answer formations was showed by green boxes to blue boxes to orange boxes.

e) The number in the bracket showed the number of students who took the framework, some students chose more than one framework for their answers.

The students' framework in Figure 2 showed that there were seven strategies they used for solving the problem 1 (about dissociation of peroxide). The first strategy was analyzed the dissociation degree (3.22\%, this was the percentage of students' number choosing the framework). Found were some errors in the solution they posed. The students thought that the word "dissociation" related to dissociation degree. The second was analyzed the radical reaction $(9.68 \%)$. The students trapped with their error understanding in recollecting their memory about chemical equilibrium to the information about the photochemical reaction. 
The third was determining the concentration constant of reaction $(6.45 \%)$, the fourth was the partial pressure $(3.22 \%)$, and the fifth was the mole of the substance $(3.22 \%)$. The third to fifth strategies were conducted by students because they preferred to organize the numerical data and inserted them to formulation what they knew without considering what the assumption should be required to use the formula or what the other factors should be kept while using the formula. The sixth determined the ICE scheme and limiting reagent (41.93\%). Only $7.69 \%$ of students that could find the conclusion to analyze the factor (such as concentration) for effective ways in posing the solution. The seventh was analyzing the factor affecting the chemical equilibrium shift $(45.16 \%)$. Because they tended to memorize the chemical equilibrium concepts, so they chose this strategy. Half of the students posed adding the catalyst to increase the forward reaction. Based on the interview with the students, they had a difficulty to discriminate the factors affecting chemical equilibrium and reaction rate. Of $21.43 \%$ students analyzed the pressure and of $14.29 \%$ students posed to not change the volume, but they had a misunderstanding about the room of furnace. Of $28.57 \%$ students analyzed the temperature, but only a quarter of them who understood the temperature would affect the effectiveness of the enzyme. Four of seven students who analyzed the concentration gave the theoretically right answer, but only two who posed the effective ways by decreasing the product.

Some students combined the strategies above because they thought so many ways to solve the problems, they did a trial and error strategy. In general, they could not give a specific way as a written solution that they had to offer to strengthen their answers. For example, they only think without finding the decision about how to change the pressure, volume, and concentration of the condition given.

The students' framework in solving the problem 2 (about ceramic production) could be found in Figure 3. From Figure 3, there were three starting states of students. Of $6.45 \%$ students began with determination between the numerical and non-numerical data. Of $6.45 \%$ began with the ceramics raw material. The dominant ways were determination of chemical equation. The first starting state was used by students to make a problem sketch. From this sketch they thought they did not need to analyze all the data but they summarized that they should increase the concentration, temperature, and pressure. The second starting state was used to control the process of ceramic production, the treatment needed, and the basis for arranging the chemical equation. And the last starting state was used by students for five reason strategies.

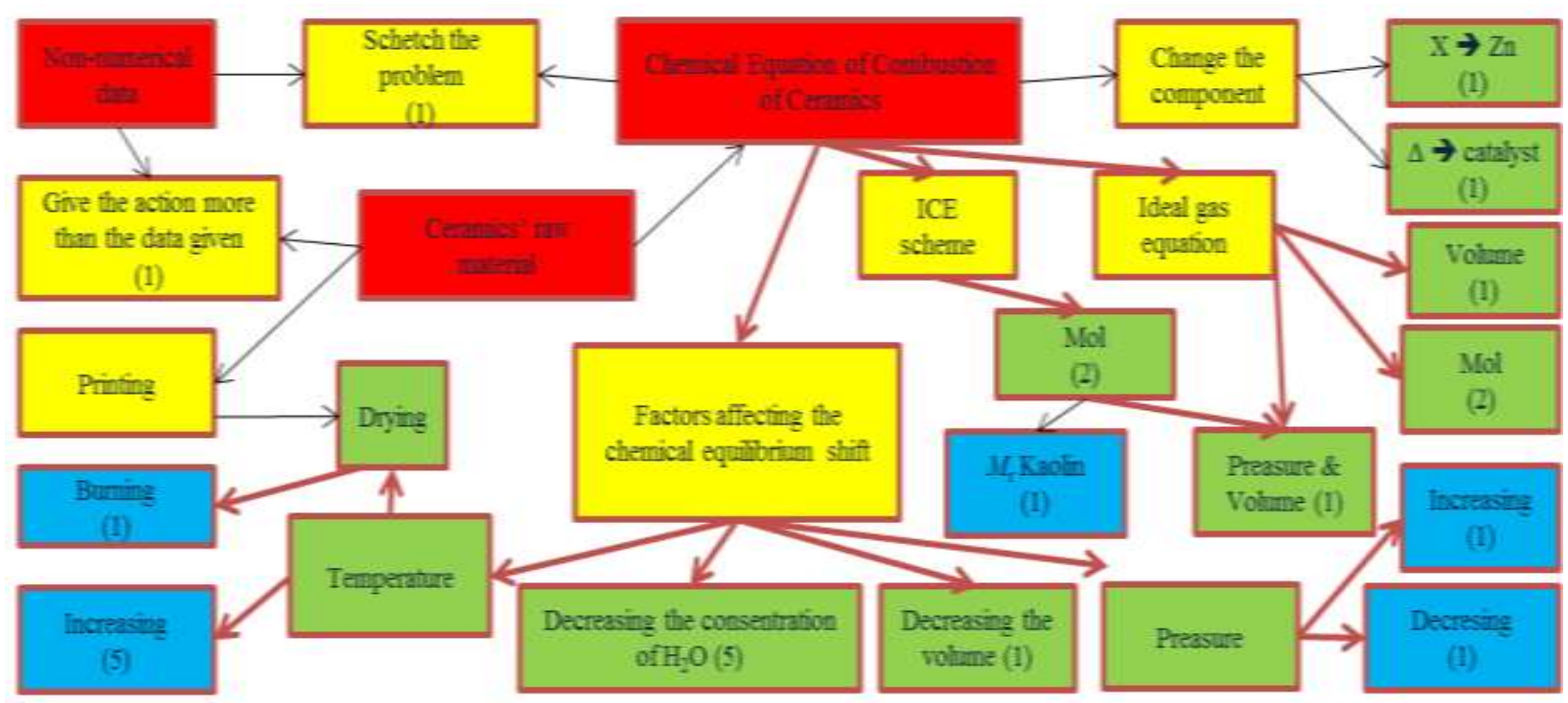

Figure 3 Distribution of Students' Framework of Problem 2

Note:

a) The Black arrow showed the ineffective ways while the red arrows showed the effective ways.

b) The red boxes showed the starting point of students' thinking

c) The yellow boxes showed the thematic strategies

d) The process of answer formations was showed by yellow boxes to green boxes to blue boxes 
e) The number in the bracket showed the number of students who took the framework, some students chose more than one framework for their answer but there were some students who left their papers in blank.

The first strategy was to change the component with another substance (5.88\%). This case was similar to the first problem. Students compared the knowledge they had before to the problem they faced, and they decided to change the symbol used in the problem to the similar memory they remembered about the symbol. The second was using the ideal gas equation (23.53\%). Students who preferred to nominal data tended to relate them to find other unknown data such as volume, mole, and gas pressure. Yet, they could not find any solution from that step. The third was determining the ICE scheme or limiting reagent (23.52\%). The students arranged the mole data from ICE to find another data but they could not find the solution. The fourth was making the problem sketch $(5.88 \%)$. This problem sketch made by students was the way to visualize the condition written on the problem. This way did not make them find the correct solution. The last strategy was analyzing the factors affecting the chemical equilibrium shift $(70.59 \%)$. In the second problem, students solved the problem based on their memories because they had could not determine the correct decision.

The students' framework in problem 3 (about bread production) was shown in Figure 4. There were two starting points for students. The first was based on the ingredient given to change the process in bread production on kneading and expanding steps. This step brought them to use the logic of the use of each ingredient. The error occurred was that they misunderstood that gluten was in the flour. This case conveyed them to make an error in conclusion. The second was based on the reaction of fermentation $(51.16 \%)$. Like the problem 1 and 2, the problem 3 showed the similar aspect to the analysis of factors in chemical equilibrium shift. A participant could not pose the idea to solve the problem after determining the bread criteria but two participants thought that the time of baking should be changed because the time was the reverse of the reaction rate. The $32.26 \%$ of participants analyzed the factors affecting the chemical equilibrium shift. They selected the frameworks because they thought the materials mentioned in the problem were in separated forms and misunderstood to the functions of the materials for making the good bread. This case indicated that participant had not analyzed in-depth all possibilities for arranging the bread criteria that was the most important step in the foundational procedural knowledge.

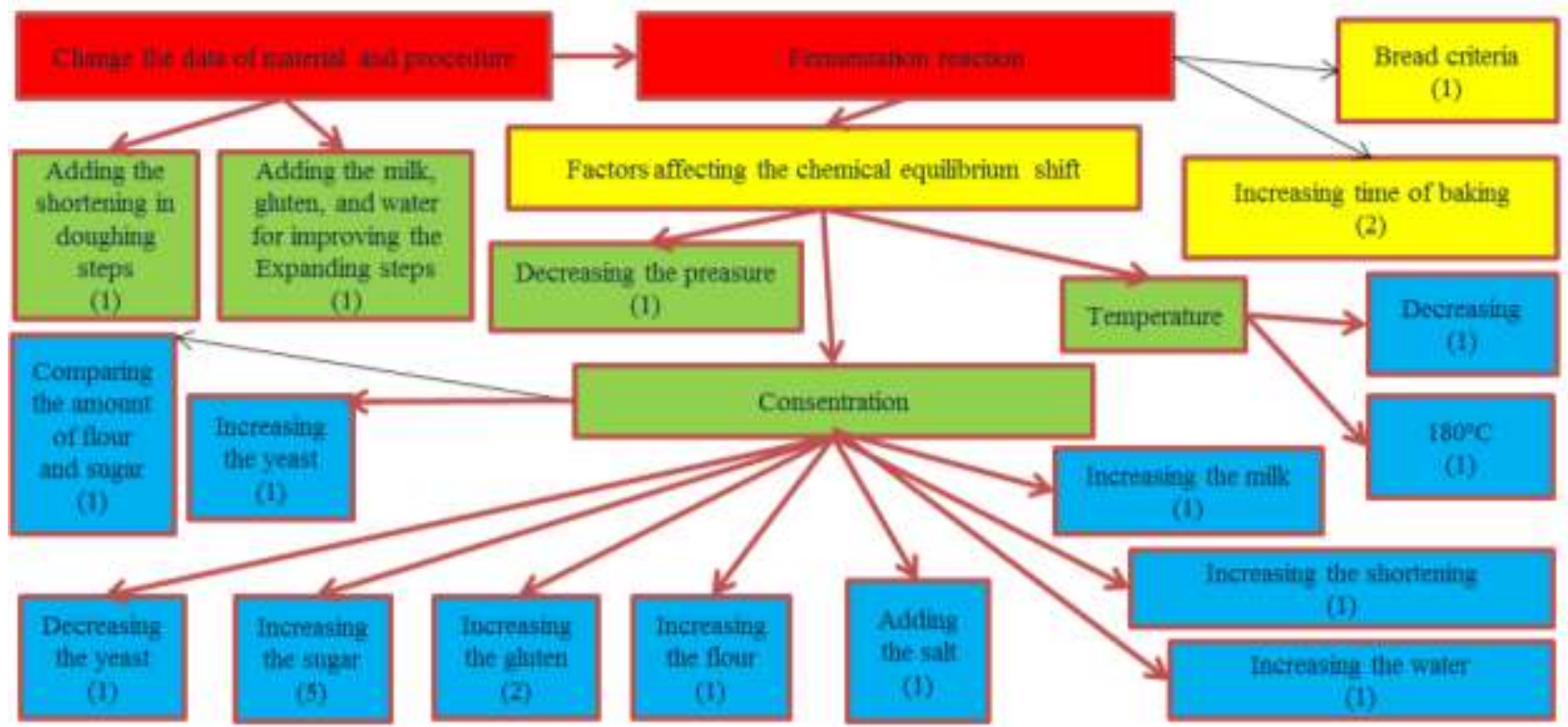

Figure 4. Distribution of Students' Framework of Question 3 
Note:

a) The Black arrow showed the ineffective ways while the red arrows showed the effective ways.

b) The red boxes showed the starting point of students' thinking

c) The yellow boxes showed the thematic strategies

d) The process of answer formations was showed by yellow boxes to green boxes to blue boxes

e) The number in the bracket showed the number of students who took the framework, some students chose more than one framework for their answer but there were some students who left their papers in blank.

From these three students' frameworks, students tended to begin from the chemical equation and used the factors affecting the chemical equilibrium as the main ways to solve the problem. From their reason from PK4, of $21.05 \%$ confessed that they did it in order to be thorough, of $21.05 \%$ said that it should like that, of $31.58 \%$ analyzed the Le Chatelier, and of $15.79 \%$ said that they only did but not understood the reason. However, $91.67 \%$ students confessed that they did not know to continue the steps when they tried to do another way. It was confirmed by the result of PK5 that of $70.97 \%$ students could not use other concepts. In PK 6, of 61.29\% students felt that they did not need to use stoichiometry if the questions were open and unclearly in the final states. This mindset affected eliciting the students' hesitation and the result of PK7 confirmed it.

Operators used in these problems were the identification of relevant data, determination of formulation and stoichiometric operation, the formation of chemical equation including the condition of reaction, combining the numerical data to factors affecting the reaction, and embedding other knowledge to find the effective factors affecting the reaction. According to the operator in each framework answer, the results of students' answers of chemical equilibrium problem-solving skills were classified into phenomenological and formalism answers. In phenomenological answers, students began their framework from the chemical equation to factors affecting the equilibrium shift. In the formalism answer, the student began their framework from the information given in the problems and related it to the stoichiometry and alternative ways to find the final states. From these research revealed, students tend to do a phenomenological answer in arranged their solution of the problem given. When they realized that the system given in the problem needed other treatments to generate the effective result, they would consider and combine other knowledge for a better solution. This result on bilingual students was contrary to the unilingual students [6]. Besides some errors in misunderstanding the problems, the bilingual students also tended to have difficulties with the chemical equilibrium concepts. False memories had been detected during this study, especially between rate reaction and chemical equilibrium concepts. This difficulty found when the students found the familiarity and recollecting the memory in consciousness $[24,25]$ and were difficult to reconstruct the recalled memories [26].

Review to the Figure 1, female students tended to be better than male students in almost the whole indicators of procedural knowledge in chemical equilibrium problem-solving. They were better in PK2, PK5, PK6, and PK7, because they did not only rivet on the numerical and chemical equation but also the condition given that should be considered. Although male was a knower, use mind, reason, rational, and scientific knowledge [27], they had a fewer grey matter in their brain so they were not more efficient in processing data [28]. Female students were able to develop the plan because their spatial-visual ability helped them to visualize, predict and determine the strength and weakness of the strategy chosen. Female students are capable of doing chemistry especially in chemical equation [29]. Female students used chemical equation because their characters such as known, nature and use feeling [27] made them used the appeared chemical symbol habitually. They often thought in-depth comprehension to fathom a meaning of the problem and grasped through linked with another knowledge like male students. Male students thought more but they could not find the gold point as result of their thoughts, so they failed in developing the strategy. Gray matter volume of female brain in frontal and parietal lobes correlated with the intelligence and was better in verbal skills [17]. Frontal lobes were involved in tracking and sense while parietal lobes relate to a calculation. It made female student had a good sense of the problem to using stoichiometry. Male students could not think and linked other knowledge they had because they only focused to analyze factor affected chemical equilibrium shift without determining other possible ways to solve the problem. 


\section{CONCLUSION}

For bilingual students, a language error would be a serious problem to understand a chemistry problem. The similarity of contents also contributed to the error happened such as reaction rate and chemical equilibrium. The best procedural knowledge of chemical equilibrium problem solving began from the best assumption determination through identification of relevant data. The failure in procedural knowledge came from when the students rivet on the numerical and chemical equation data and related them to the factors affecting the equilibrium shift without analyzing others factors that will impact the reaction. If there was no misconception, they tend to be a phenomenological answer. When all data were combining without correct correlation and conceptions, they will fail either the phenomenological or formalism answer.

This present study suggests to both bilingual and unilingual students to build the correct foundational procedural knowledge (making the assumption, developing the strategy, and determining the chemical equation) for better and effective frameworks in chemical equilibrium problem-solving skills. Male students should try to think holistically, to consider any possibility on the error of the solution, and to make sure that your basic understanding of chemical equilibrium is correct especially on a similar topic like the reaction rate. Female students should sharpen their assumptions when face the ill-structured problem, by strengthening this item they can make sure what the functions of numerical data for arranging the solution and can be avoided from the traps of similar conceptions and misunderstanding of the problem given.

The teacher should often train their students to think and apply the chemical equilibrium concept to contextual problems. For training the bilingual students, teachers should be careful to indoctrinate the concept to their students and always conduct the diagnostic or formative test for anticipating the mistakes. The guiding framework should be limited to disclose the insight and to expand the students' understanding of open-ended problems and their possible operators to find the solution. Presenting the contextual-problembased learning would help increase the chemical equilibrium problem-solving skills in teaching and learning process.

\section{ACKNOWLEDGEMENTS}

Thank you to Indonesia Endowment Fund for Education (LPDP) for supporting this research.

\section{REFERENCES}

[1] Johnstone, A. H. (2006). Chemistry Education Research and Practice,7(2), 49-63.

[2] Ghirardi, M., Marchetti, F., Pettinari, C., Regis, A., \& Roletto, E. (2015). Journal of Chemical Education, 92 , 1008-1015.

[3] Pedrosa, M. A., \& Dias, M. H. (2000).Chemistry Education Research and Practice in Europe, , 1, $227-236$.

[4] Raviolo, A., \& Garritz, A. (2009). Chemistry Education Research and Practice, 10, 5-13.

[5] Kousathana, M., \& Tsaparlis, G. (2002). Chemistry Education Research and Practice in Europe, 3, 5-17.

[6] Ganaras, K., Dumon, A., \& Larcher, C. (2008). Chemistry Education Research and Practice, 9, $240-249$.

[7] Dunlosky, J., \& Metcalfe, J. (2009). Metacognition, Sage.

[8] Eldar, O., Eylon, B., \& Ronen, M. (2012). A metacognitive teaching strategy for preservice teachers: Collaborative diagnosis of conceptual understanding in science, in: A. Zohar \& Y. J. Dori, Metacognitive in Science Education: Trends in Current Research, Springer, 225-250.

[9] Favieri, A. G. (2013). Electronic Journal of Research in Educational Psychology, 11, 831-850.

[10] Schraw, G., \& Dennison, R. S. (1994). Contemporary Educational Psychology, 19, 460-475.

[11] Sperling, R. A., Howard, B. C., \& Staley, R. (2004). Educational Research and Evaluation, 10, $117-139$. 
[12] Schraw, G., Olafson, L., Weibel, M., \& Sewing, D. (2012). Metacognitive knowledge and field-based science learning in an outdoor environmental education program, in: A. Zohar \& Y. J. Dori, Metacognitive in Science Education: Trends in Current Research, Springer, 57-77.

[13] Cheung, D. (2009). Chemistry Education Research and Practice, 10, 97-108.

[14] St. Clair-Thompson, H., Overton, T., \& Bugler, M. (2012). Chemistry Education Research and Practice, 13, 484-489.

[15] Abir, A., \& Dori, Y. J. (2013). Educacion Quimica, 24, 37-43.

[16] Pettito, L., \& Dunbar, K. N. (2009). Mind Brain Education, 3(4), 185-197.

[17] Cosgrove, K. P., Mazure, C. M., \& Staley, J. K. (2007). Biology Psychiatry, 62(8), 847-855.

[18] Zhu, Z. (2007). International Educational Journal, 8(2), 187-203.

[19] Mourtos, N. J., Okamoto, N. D., \& Rhee, J. (2004). Defining, Teaching, and Assessing Problem Solving Skills, in: Proceeding on 7th UICEE Annual Conference on Engineering Education Mumbai, India.

[20] Yodi, B., Hairida, \& Lestari, I. (2015). Jurnal Pendidikan dan Pembelajaran, 4, 5.

[21] Favieri, A. G. (2013). Electronic Journal of Research in Educational Psychology, 11(3), 831-850.

[22] Snyder, L. S., \& Snyder, M. J. (2008). The Delta Pi Epsilon Journal, 1(2), 90-99.

[23] Sadowski, C., \& McIntosh, J. E. (2015). Journal of Phenomenological Psychology, 46, 69-104.

[24] Johansson \& Stenberg. (2002). Scandinavian Journal of Psychology, 43, 369-383.

[25] Reodiger, H. L. III., \& McDermott, K. B. (1995). Journal of Experimental Psychology: Learning, Memory, and Cognition, 21(4), 803-814.

[26] Anderson, M. C., Bjork, R. A., \& Bjork, E. L. (1994). Journal of Experimental Psychology: Learning, Memory and Cognition, 20(5), 1063-1087.

[27] Seth, Aliah \& Marlina. (2007). Laporan Teknikal Vot 75161 Fakulti Pendidikan Universiti Teknologi Malaysia.

[28] Chamberlain, L. B. (2009). Child Law Practice, 28(2), 17-24.

[29] Eriba, J. O., \& Ande, S. (2006). Educational Research and Reviews, 1(6), 170-173. 